\title{
Nutrient and phytonutrient quality of nutricereals incorporated flour mix suitable for diabetics
}

\author{
M. Mounika and T.V. Hymavathi* \\ Department of Foods and Nutrition, Postgraduate and Research Centre, Professor Jayashankar Telangana State Agricultural University, \\ Hyderabad-500030, Telangana State, India \\ *Department of Foods and Nutrition, Postgraduate and Research Centre, Professor Jayashankar Telangana State Agricultural University, \\ Hyderabad-500030, Telangana State, India.
}

\section{Article Info}

Article history

Received $1^{\text {st }}$ March 2021

Revised 18 April 2021

Accepted 20 April 2021

Published online 30 June 2021

\section{Keywords}

Millets

Proximate

Phytochemicals

Antinutrients

Flour mix

\begin{abstract}
Diabetes is a health problem whose burden is evident in developing countries, and over the decades, it has been drastically increasing at the global level. It became one of the causes of death. Diet is one of the interventions to control diabetes. Consumption of millets or whole grains with pulses is associated with lowering non-communicable diseases, as they contain a large amount of dietary fiber, minerals, phenolics, and antioxidants. The current study was aimed to develop a product from millets suitable for consumption by people with diabetes. Selected millets, viz., foxtail millet, proso millet, kodo millet and barnyard millet were procured from the local market. Wheat flour (Triticum aestivum L.), green-gram dhal (Phaseolus aureus Roxb), oats, soybean (Glycine max Merr), barley, fenugreek seeds, and gums were procured from the local market. Flour mixes were prepared by mixing dehulled, milled millet flours with other grain flours in different proportions, keeping $100 \%$ whole wheat flour as control. All the flour samples were tested for nutrients and phytonutrients using AOAC methods. The moisture content, total carbohydrate, and energy content were decreased; protein, crude fiber, ash, and lipid contents were increased significantly $(p<0.01)$ with the incorporation of millet flour blend in minor millet flour mix (MMFM) compared to control flour. Antioxidant and phytonutrients, viz., total phenols, and phytic acid content were high in the MMFM.
\end{abstract}

\section{Introduction}

Diabetes is a global public health problem whose burden is evident in developing countries such as India (Kaveeshwar and Cornwall, 2014). According to the Indian Diabetes Federation (2019), 463 million people had diabetes in the world. The global prevalence of diabetes is estimated to be 578 million by 2030, and India had an $8.3 \%$ prevalence with the second rank in the world. One of the major strategies in controlling diabetes is maintaining effective glucose levels. Fasting plasma glucose $\geq 126 \mathrm{mg} / \mathrm{dl}$ after two hours post-load glucose $\geq 200 \mathrm{mg} / \mathrm{dl}$, HbA1c $\geq 6.5 \%$ (ADA, 2018). Regular consumption of plant-based foods containing bioactive compounds like protein, fiber, and phytochemicals are associated with fewer digestive disorders, reduced colon cancer rate, better blood-sugar control, and lower blood cholesterol levels.

The management of Type II diabetes mellitus needs diet modification which includes a diet high in complex carbohydrates, protein, fiber, and low in fat, which does not cause a rapid rise in blood glucose levels. The slower the rate of carbohydrate absorption, the lower is the rise in blood glucose level and the glycaemic index

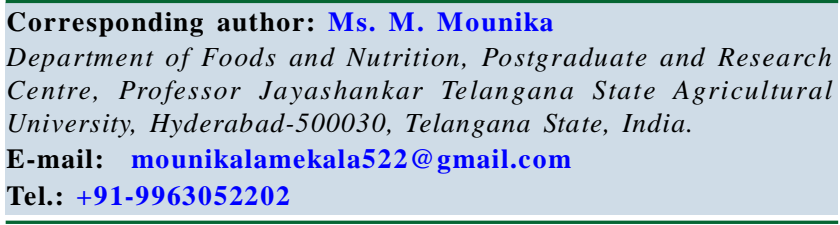

Tel. +91-9963052202

value. Significant alterations in the glycemic index and dietary fiber content of meals were known to include small but significant glucose profile changes (Karuppaswamy, 2013). Millets are small seeded grains with a rich dietary fiber source that provides a wide range of nutrients and phytochemicals, including vitamin E, magnesium, and folate that optimize health. Millets contain a higher proportion of unavailable carbohydrate and the release of sugar from millets. They contain water-soluble gum and $\beta$-glucan which help improve glucose metabolism. Millets contribute to antioxidant activity through phytates, polyphenols, and tannins present in them, having an essential role in ageing and metabolic diseases (Bravo, 1998). Therefore, millets are suitable for a diabetic diet, but the characteristic flavour and difficulty in the processing are the limitations for its incorporation into the diet (Vijayalakshmi and Radha., 2006). Millets are called diabetic-friendly grains due to high macronutrients and dietary fiber content, low digestion, and low sugar release and millets have a low glycemic index compared to other cereals. The legumes and pulses have been known as a poor man's meat. They supply protein, complex carbohydrates, fiber, and essential vitamins and minerals to the diet, which are low in fat and sodium and contain no cholesterol (Priyanka et al., 2018).

Millets are traditionally used in the form of unleavened bread (roti), dumplings, porridge, and desserts. Most commonly followed conventional processing methodologies for millets are milling, including decortications and size gradation, popping, malting, fermentation, and cold extrusion (Kotagi et al., 2013). Composite 
flour technology refers to the process of mixing various cereal-based flour with pulse and legume flours to produce high-quality food products economically. Formulation of composite flour is vital for the development of value-added products with optimal functionality. They have not only better nutritional quality but also the necessary attributes for consumer acceptance. The nutritional value for cereal flours that are poor in lysine but rich in sulfur-containing amino acids is improved by adding legume flours (Kadam et al., 2012). A multigrain flour helps in a high intake of fiber and health-enhancing components (Ragaee and Abddel Aal, 2006).

Hence, the present study was taken up to develop value-added minor millet flour mix by using the locally available cereals, millets, pulses for multipurpose usage and fit into the people's general lifestyle.

\section{Materials and Methods}

\subsection{Raw materials procurement and sample preparation}

Whole foxtail millet, proso millet, kodo millet, and barnyard millet were procured from the local market. Millet grains were dehulled in an abrasive dehuller (Gurunanak Engineering Co, Hyderabad) to achieve $17 \%$ removal of the bran and the dehulled grains collected through bottom opening along with hull. Then to obtain dehulled grain, bran was separated by winnowing. Wheat flour (T. aestivum), green-gram dhal ( $P$. aureus ), oats, soybean (G. max), barley, fenugreek and gums seeds were procured from the local market. An electronic weighing balance (Model AB204) was used to weigh the chemicals and samples for the study. Hot air oven (Deccan Coporation ISO 9001:200 certified company) was used to determine samples' moisture content. Gallic acid, FolinCiocalteu's reagent, phytic acid, and enzymes for digestion of starch and dietary fiber estimation, pepsin, pancreatin, Termamyl (A 3403), and amyloglucosidase were from M/s Sigma Chemical Co. (St. Louis, MO, USA). All the chemicals used for the study were laboratory reagent (LR) and analytical reagent (AR) grades.

Table 1: Ingredients proportions for preparation MMFM

\begin{tabular}{|l|l|}
\hline Ingredients & MMFM (\%) \\
\hline Foxtail millet & 12.5 \\
Proso millet & 12.5 \\
Kodo millet & 12.5 \\
Barnyard millet & 12.5 \\
Wheat & 25 \\
Green gram & 6 \\
Barley & 6 \\
Oats & 6 \\
Soya & 5 \\
Fenugreek & 1 \\
Gums & 1 \\
\hline
\end{tabular}

2.2 Preparation of flour mix

All dehulled millets and other grains were dried in tray dryer (Sowbagya Industries, Kolakalur, Tenali)) for $4 \mathrm{~h}$ at low temperature $\left(40^{\circ} \mathrm{C}\right)$ and each grain was milled into flour in a pulveriser (Able manufacturers, Hyderabad). All flours were mixed in different proportion as mentioned in Table 1, then mixed flour mix was sieved through 40 size mesh toobtain uniform sized particles. The control mix was prepared using $100 \%$ wheat flour and MMFM (minor millet flour mix) was prepared as per the proportions shown in Table 1. The developed mixes were packed in a polythene (PE) bag and stored at $30^{\circ} \mathrm{C}$ until further analysis.

\subsection{Proximate analysis}

Proximate content of flour mixes were analyzed using standard protocols.

\subsubsection{Moisture}

Standard protocol (IS:1155-1968 reaffirmed 2010) was used for moisture estimation. Briefly, $5 \mathrm{~g}$ of the sample was dried at $105 \pm$ $3^{\circ} \mathrm{C}$ for $2 \mathrm{~h}$ in a hot air oven. After $2 \mathrm{~h}$, sample was cooled in a desiccator and weighed. This was repeated at $30 \mathrm{~min}$ intervals till constant weight was achieved. The moisture content of the sample was expressed in $\mathrm{g} / 100 \mathrm{~g}$ of sample.

\subsubsection{Protein}

Crude protein was estimated using the microKjeldahl method (AOAC 954.01-2010) using Pelican Kelplus equipment, calculated by multiplying with a factor $\mathrm{N} \times 6.25$ expressed as $\mathrm{g} / 100 \mathrm{~g}$.

\subsubsection{Fat}

Soxhlet method (AOAC 922.06 - 2007) was employed to estimate fat content and expressed as $\mathrm{g} / 100 \mathrm{~g}$.

\subsubsection{Crude fiber}

Moisture and fat-free samples were utilized for estimating crude fiber. Samples were treated with acid followed by an alkali bath as described in standard AOAC 962.09 - 2007 protocol. The residue obtained after final filtration was weighed, incinerated, cooled, and weighed again. Crude fiber content was expressed as $\mathrm{g} / 100 \mathrm{~g}$ of the sample.

\subsubsection{Ash}

Total ash was estimated using a standard protocol (IS:1155-1968 reaffirmed 2010), where $5 \mathrm{~g}$ of dried sample was weighed in a crucible, ignited till it was charred completely. The charred sample was then transferred to the crucible and kept in the muffle furnace for about $4 \mathrm{~h}$ at $600^{\circ} \mathrm{C}$ till white or greyish color ash was obtained. It was then cooled in a desiccator and weighed after reaching room temperature.

\subsubsection{Total carbohydrate (g/ $100 \mathrm{~g})$}

$100-[$ Protein $(\mathrm{g})+$ Fat $(\mathrm{g})+$ Crude fibre $(\mathrm{g})+$ Ash $(\mathrm{g})+$ Moisture $(\%)]$

\subsubsection{Computation of energy}

Energy was calculated for all the samples with the following formula: Energy $(\mathrm{Kcal} / 100 \mathrm{~g})=[$ Protein $(\mathrm{g}) \mathrm{x} 4]+[$ Carbohydrate $(\mathrm{g}) \times 4]+$ [Fat $(\mathrm{g}) \times 9]$

\subsection{Estimation of mineral content}

Moisture-free flour samples were wet digested in a microwave digester using nitric acid. Further iron, calcium, zinc content was 
determined as described in standard protocol (AOAC 975.03) using atomic absorption spectrophotometry and sodium, and potassium were estimated using flame photometry (AOAC, 956.01).

\subsection{Estimation of total dietary fiber}

Total dietary fiber was determined using a standard protocol (Asp and Johansson, 1981), based on enzymatic and gravimetric methods. The samples (moisture and fat-free) were weighed accurately, subject to gelatinization with heat-stable a-amylase, and then digested with protease followed by amyloglucosidase for removing starch and protein content in the samples. Further, the samples were treated with ethanol for the precipitation of soluble dietary fiber. The residue was then filtered, washed with ethanol and acetone, followed by drying. Half of the samples were then analyzed for protein and another half for ash. Total dietary fiber was calculated as the weight of residue minus the weight of protein and ash.

\subsection{Sample extraction for antioxdiants and phytonutrient} analysis

Phytonutrients (Total phenols, flavonoids and phytic acid) and antioxidant activity (DPPH) was estimated for both samples.

Flour samples were accurately weighed $(0.5 \mathrm{~g})$ in a conical flask to which $15 \mathrm{ml}$ of $80 \%$ acidified methanol ( $\mathrm{pH} 2.0$ ) was added. The mixture was extracted by continuous shaking $(155 \mathrm{rpm})$ at room temperature for $30 \mathrm{~min}$, and the supernatant was collected. The residue was re-extracted twice, and all three collected supernatants were centrifuged at $6000 \mathrm{rpm}$ for $15 \mathrm{~min}$ and filtered using Whatman No. 1 filter paper. The volume of the extract was noted and made to $50 \mathrm{ml}$ using a solvent. The extracts were transferred to centrifuge tubes and stored at $-20^{\circ} \mathrm{C}$ till further use. This extract was used to determine total phenol (TP), flavonoids and 1,1-diphenyl-2picrylhydrazyl (DPPH).

\subsection{Estimation of total phenoliccontent (TPC)}

Total phenolic content of samples was determined using FolinCiocalteu reagent according to the method of Slinkard and Singleton (1977) using gallic acid as a standard phenolic compound. Briefly, $1 \mathrm{ml}$ of approximately diluted samples and a standard solution of gallic acid were added to a $25 \mathrm{ml}$ volumetric flask containing $9 \mathrm{ml}$ of distilled water. A reagent blank using distilled water was prepared. $1 \mathrm{ml}$ of Folic-Ciocalteu phenol reagent was added to the mixture and shaken. After $5 \mathrm{~min}, 10 \mathrm{ml}$ of a $7 \% \mathrm{Na}_{2} \mathrm{CO}_{3}$ solution was added with mixing and then allowed to stand for $2 \mathrm{~h}$. The absorbance was measured at $760 \mathrm{~nm}$ using Shimadzu UV spectrophotometer (model: UV-1800, Japan). The gallic acid standard curve $(5 \mu \mathrm{g}-35 \mu \mathrm{g})$ was prepared. TP content was determined from standard curve $(\mathrm{y}=$ $\left.0.0113 \mathrm{x}+0.0148 ; \mathrm{R}^{2}=0.992\right)$ and expressed as $\mathrm{mg}$ gallic acid equivalent (GAE) $\mathrm{mg} / 100 \mathrm{~g}$ of the sample. The concentration of total phenolic compounds in the samples was determined as a microgram of gallic acid equivalent using an equation obtained from a standard gallic acid graph.

Calculation: Std .conc/Std O.D /Aliquot taken * volume made up /sample taken $* 100 / 1000 *$ dilution factor.

\subsection{Estimation of total flavonoids content (TFC)}

Flavoniod content of samples was estimated using Zhishen et al. (1999) method.

\subsection{Estimation of DPPH radical scavenging activity (DSRA)}

The flour mixes' free radical scavenging capacity was determined using 1,1-diphenyl-2- picryl- hydrazil (DPPH) (Dorman et al., 2004). Two milliliters of a methanol solution of DPPH radical in the concentration of $0.05 \mathrm{mg} / \mathrm{ml}$ and $1 \mathrm{ml}$ of extract were placed in cuvettes and allowed to stand at room temperature for $30 \mathrm{~min}$ after shaking. Then, the absorbance was measured at $517 \mathrm{~nm}$ against methanol as blank in a spectrophotometer. The DPPH free radical concentration was calculated using the following equation:

Calculation: percent inhibition $=[(\mathrm{AC}-\mathrm{AE}) / \mathrm{AC}] * 100$

(where, $\mathrm{AC}=$ absorbance of control $; \mathrm{AE}=$ Absorbance of extract)

\subsection{Estimation of phytic acid}

Phytic acid content of samples was estimated using Wheeler and Ferrel (1971) procedure.

\subsection{Estimation of In vitro protein digestibility}

IVPD of samples was estimated according to the procedure of Singh and Jambunathan (1981).

\subsection{Estimation of resistant starch}

Resistant starch estimated using Goni et al.( 1996).

\subsection{Statistical analysis}

All experiments were performed three times. All data presented as means \pm standard deviation of the mean. As for multiple group comparisons, the significance of the differences among the treatment groups and their respective control groups were analyzed using WINDOW STAT 9.1 software. Statistical significance was assessed by one-way analysis of variance (ANOVA). Differences between means were considered statistically significant at $5 \%$ level $(p<0.05)$.

\section{Results}

\subsection{Proximate composition of the flour mixes}

Grain quality, processing, the combination of grains, and the moisture content may affect the developed flour mix's nutritional composition. The proximate composition estimated, for each nutrient is summarized and presented in Table 1. All the values are presented on a dry weight basis.

\subsubsection{Moisture}

There was a significant difference $(p<0.01)$ in moisture between the control flour $10.44 \mathrm{~g} / 100 \mathrm{~g}$ and minor millet flour mix (MMFM) $9.47 \mathrm{~g} / 100 \mathrm{~g}$ (Table 1). The present results were close to millet flours' moisture content (10.01\% to $12.17 \%$ ) reported by Singh $e t$ al. (2005). Chaudhary and Jood (2013) reported a higher moisture content in wheat flour.

\subsubsection{Protein}

Significantly $(p<0.05)$ higher protein content was observed in MMFM (11.42 g/100 g) than that of control $(7.39 \mathrm{~g} / 100 \mathrm{~g})$. The addition of different millets and pulses lead to a $35.2 \%$ increase in protein. The present results were in agreement with (Poongodi and Mohankumar, 2009) where, formulated millet based composite flour mix contained maximum protein. This increase in protein 
content in flour could be attributed to the significantly higher protein content of individual flour components, viz., soya flour that was incorporated in flour formulation. A high protein diet is good for the health of diabetics because it supplies essential amino acids needed for tissue repair. Protein does not raise blood glucose during absorption as do carbohydrates, and it does not supply as many calories as fats. In type 2 diabetics, protein and carbohydrate consumption lowers the blood glucose concentration sulfurcontaining amino acid stimulation of insulin secretion and promotes satiety (Anitha and Philip, 2001; Srilakshmi, 2001).

\subsubsection{Fat}

Similar to protein, fat content was also significantly higher in millet flour mix $(4.44 \mathrm{~g} / 100 \mathrm{~g})$ than that of control $(1.5 \mathrm{~g} / 100 \mathrm{~g})$ (Table 2). Lakshmi et al. (2015) reported that compared to control bread
(1.84\%), experimental composite flour bread (V-I, V-II and V-III were $3.37,4.75$ and $5.64 \%$, respectively) had higher fat contents. It was observed from the results that the increase in fat content for the millet flour mix can be attributed to minor millets, which have higher fat content compared to wheat (Ahmed et al., 2013). As the increase in fat is not due to the external addition, there would not be any deleterious effects on health. This feature also highlights the possibility of using high-fat seed flours like millet as sources of natural fat replacers.

Fat delays gastric emptying delayed gastric emptying has the effect of decreased glycemic response to a meal. After a fat meal, gastric inhibitory polypeptide level increases; this potentiates glucoseinduced insulin secretion initially, hence after 4hour fat may reduce insulin secretion, possibly due to the presence of chylomicrons or increased free fatty acids (Lin et al., 1996).

Table 2: Proximate composition of control flour and MMFM (\%/100 g)

\begin{tabular}{|l|l|ll|ll|l|l|}
\hline Samples & Moisture & Ash & Protein & Fat & Crude fiber & CHO(g) & Energy(Kcal) \\
\hline Control flour & 10.44 & 1.556 & 7.39 & 1.55 & 1.30 & 77.05 & 354.1 \\
MMFM & 9.472 & 2.263 & 11.425 & 4.488 & 5.23 & 67.07 & 270.72 \\
S.E & 0.04073 & 0.01504 & 0.03723 & 0.0782 & 0.027 & 0.05065 & 1.47984 \\
\hline
\end{tabular}

S.E, Standard error; MMFM, minor millet four mix.

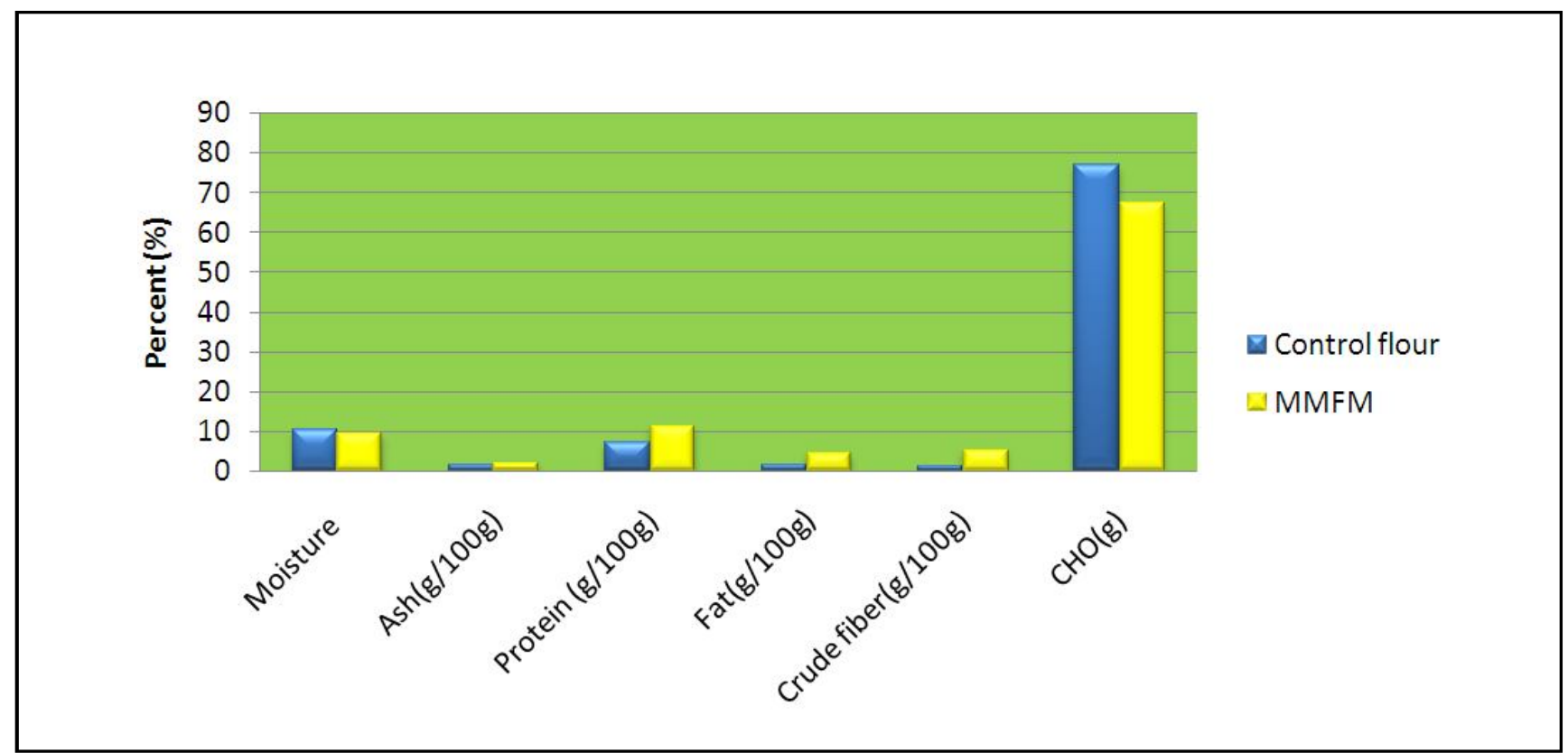

Figure 1: Proximate composition of flour mixes.

\subsubsection{Crude fiber}

Similar to protein and fat, the crude fiber content was also significantly $(p<0.05)$ higher $(75.1 \%)$ in MMFM $(5.23 \mathrm{~g} / 100 \mathrm{~g})$ than in control flour mix with $(1.3 \mathrm{~g} / 100)$. Similar results reported by Laxshmi et al. (2015) fiber content in composite flour bread (1.9 $\%$ ) and in three millet included bread variations as 2.1, 2.3 and $2.4 \%$ for V-I, VII and V-III, respectively. Thus, it can be attributed to fibre-rich millets grains. The fiber content increases significantly $(p<0.05)$ due to the modification of the structure of cell wall polysaccharides of the seeds, possibly affecting the intactness of tissue histology and disrupting the protein carbohydrate interaction. This involves extensive cell wall biosynthesis and, therefore, new dietary fiber production (Martin-Cabrejas et al., 2003). The nutritional characteristics of composite whole wheat flour were gradually increased for dietary fiber, ash, protein, and fat contents. A blend of chickpea split without husk, barley, soybean, and fenugreek seeds was added from 0 to $40 \%$ (Indrani et al., 2011). 


\subsubsection{Carbohydrate}

The control flour (77.0 g) had high carbohydrate, and MMFM $(67.0 \mathrm{~g})$ had lower carbohydrate, other pulse, legumes incorporation significantly reduced the carbohydrate content of experimental flour by $12.5 \%$ from control (Table 2). Similar results were reported by Deepa (2009) where, wheat flour (control flour) contained 70.37 per cent carbohydrate while $30 \%$ incorporated millet based composite flour had 54.26 per cent of carbohydrate. Malathi et al. (2014) reported that $50 \%$ kodo millet incorporated chapathi had 54.12 of carbohydrate which is lower than the control chapathi, the difference in carbohydrate contents was attributed to the incorporation of low carbohydrate cereals in flour mix. In the present study, the decrease in the composite flour's carbohydrate content was due to the dilution effect of pulses, legumes, oats, and barley flours, which are low in carbohydrates. Complex carbohydrates are advised for diabetics; high fibre foods are encouraged to reduce the rate of absorption of glucose from the gut (Jenkins et al., 1978).

\subsubsection{Energy}

The control flour (354.1) had high energy, and the MMFM had lower energy (270.7 Kcal) (Table.1); millet, pulse, legumes incorporation significantly $(p<0.05)$ reduced the energy content of experimental flour with a percentage change of $23.6 \%$ from the control. Dietary management of energy (calories) intake is vital in diabetes (Deepa, 2009).

\subsection{Minerals}

The results presented in Table 3, exhibits a significant difference in minerals of control and millet flour mix.

Table 3: Mineral content of MMFM and control flour

\begin{tabular}{|l|l|l|}
\hline Minerals & Control flour & MMFM \\
\hline $\mathrm{Ca}(\mathrm{mg} / 100 \mathrm{~g})$ & $49.1 \pm 0.24$ & $52.9 \pm 0.04^{*}$ \\
$\mathrm{Zinc}(\mathrm{mg})$ & $29.8 \pm 0.38$ & $33.3 \pm 0.36^{*}$ \\
Iron $(\mathrm{mg} / 100 \mathrm{~g})$ & $4.67 \pm 0.02$ & $5.56 \pm 0.08^{*}$ \\
Potassium $(\mathrm{mg} / 100 \mathrm{~g})$ & $34.7 \pm 0.42$ & $44.2 \pm 1.58^{*}$ \\
Sodium $(\mathrm{mg} / 100 \mathrm{~g})$ & $0.02 \pm .008$ & $0.158 \pm 0022^{*}$ \\
\hline
\end{tabular}

Note: * = significantly different at $5 \%$

\subsubsection{Calcium}

The incorporation of millets and other grains in the wheat flour $(p<0.01)$ affected the mix's calcium content. It was increased by $7.1 \%$ (from 49.16 to $52.95 \mathrm{mg} / 100 \mathrm{~g}$ of control and experimental, respectively). The results were in agreement with Karuppaswamy et al. (2013). Compared to the control bread (20.61 mg), minor millets added formulations T1V1(kodo millet bread) $(21.54 \mathrm{mg})$ and T2V2 (little millet bread) $(22.21 \mathrm{mg}$ ) had higher calcium content. The increasing trend in composite breads calcium content was possibly due to the higher calcium content of minor millets.

Kulakarni et al. (1991) reported that a multigrain mix contained higher calcium than little millet-based counterpart irrespective of green leafy vegetables used. Multigrain or little millet mix with chakramuni leaves had a significantly higher amount of calcium (61.46 $\mathrm{mg}$ and $60.12 \mathrm{mg} / 100 \mathrm{~g}$, respectively), compared to amaranthus incorporated mixes $(58.78 \mathrm{mg}$ and $54.78 \mathrm{mg} / 100 \mathrm{~g}$, respectively).

\subsubsection{Zinc}

It was observed that the zinc content was $33.31 \mathrm{mg}$ and $30 \mathrm{mg} / 100$ g) in MMFM and control flour, respectively. The results showed that incorporating millet significantly affected the millet flour mix's zinc content with a 9.24 per cent rise from control flour. Minerals are essential for body growth and development, functioning, immune functioning. Zinc plays an important role in the synthesis, storage, and secretion of insulin and conformational integrity of insulin in hexameric form. The decreased zinc affects the ability of islet cells to produce and secret insulin, particularly in type 2 diabetics (Chausmer, 1998).

\subsubsection{Iron}

From the results, it was observed that the incorporation of millet significantly influenced the content of different minerals in the minor millet based flour. MMFM had a significantly higher iron content than control flour by $46 \%$ as shown in Figure 2.

\subsubsection{Sodium}

The sodium content varied between flours and MMFM had higher $(0.158 \mathrm{mg} / 100 \mathrm{~g})$ than in control flour $(0.02 \mathrm{mg} / 100 \mathrm{~g})$ (Table.3). The variation in sodium content between samples was found statistically significant $(p<0.05)$.

\subsubsection{Potassium}

The incorporation of millets and other grains in the wheat flour $(p<0.01)$ affected the mix's potassium content. It was increased by $21.4 \%$ (from 34.76 to $44.29 \mathrm{mg} / 100 \mathrm{~g}$ of control and experimental, respectively). The variation between the samples was found statistically significant $(p<0.05)$. According to Preuss (2001), a high intake of potassium can protect against increased blood pressure and other cardiovascular risks. Results indicated the addition of millets increased the potassium content of flour.

\subsection{Resistant starch}

Resistant starch (RS) was significantly high $(p<0.05)$ in MMFM $(32.4 \mathrm{~g})$ than in control flour $(27.52 \mathrm{~g} / 100 \mathrm{~g})$ (Table.4). RS is not digested and absorbed by humans as energy. It has a positive role against diabetes. Johnston et al. (2010) has discovered that the consumption of resistant starch improves insulin sensitivity. It does not aûect body weight, fat storage in muscle, liver, or visceral depots signiûcantly.

\subsection{Dietary fiber}

The MMFM had higher dietary fibre $21.158 \mathrm{~g} / 100 \mathrm{~g}$, and control flour had lower DF with 13.84/ 100g. Similar results reported by Hameeda et al. (2012) dietary fiber varied from $12.4 \mathrm{~g}-16.5 \mathrm{~g}$ in multigrian mixes.

\subsection{In vitro protein digestibility (IVPD)}

As shown in Table 4 IVPD content in control and MMFM was $55.0 \%$ and $62 \%$, respectively. Results indicated that the addition of pulses, legumes could increase the protein digestibility of flours. Similar results were reported by Sujatha et al. (2015) were, the dehulled foxtail millet(56.0) had the highest IVPD followed by sorghum (55.8) and pearl millet (52.17). Similar results were also 
reported by Laminu et al. (2011) in pearl millet based weaning blends. However, the protein concentrates from yellow millet (foxtail millet), white millet (foxtail millet), soy beans were reported as $78 \%, 81,84 \%$, respectively Tabita et al. (2009).

Table 4: Resistant starch, IVPD, dietary fiber and phytonutrient content of flours

\begin{tabular}{|c|c|c|c|c|c|c|c|}
\hline Samples & RS (\%) & $\begin{array}{l}\text { Dietary } \\
\text { fiber(\%) }\end{array}$ & IVPD (\%) & $\begin{array}{l}\text { Total phenols } \\
\text { (GAE mg/100 g) }\end{array}$ & $\begin{array}{l}\text { Antioxidants } \\
(\mathrm{mg} / 100 \mathrm{~g})\end{array}$ & $\begin{array}{l}\text { Flavonoids } \\
\text { (REmg/100 g) }\end{array}$ & $\begin{array}{l}\text { Phytic acid } \\
(\mathrm{mg} / 100 \mathrm{~g})\end{array}$ \\
\hline Control flour & 27.52 & 13.85 & 55.43 & 106.9 & 85.70 & 152.0 & 206.4 \\
\hline MMFM & $32.31 *$ & $21.16^{*}$ & $62.86 *$ & $240.2 *$ & $93.33 *$ & $164.0 *$ & $278.2 *$ \\
\hline S.E & 0.32526 & 0.11099 & 0.35061 & 0.04583 & 0.43462 & 0.63853 & 1.32626 \\
\hline
\end{tabular}

RS: resistance starch; IVPD, In vitro protein digestibility; S.E, Standard error; GAE, Galic acid equivalent; RE, rutinequivalent; *, significantly different at $5 \%$ level $(p<0.01)$.

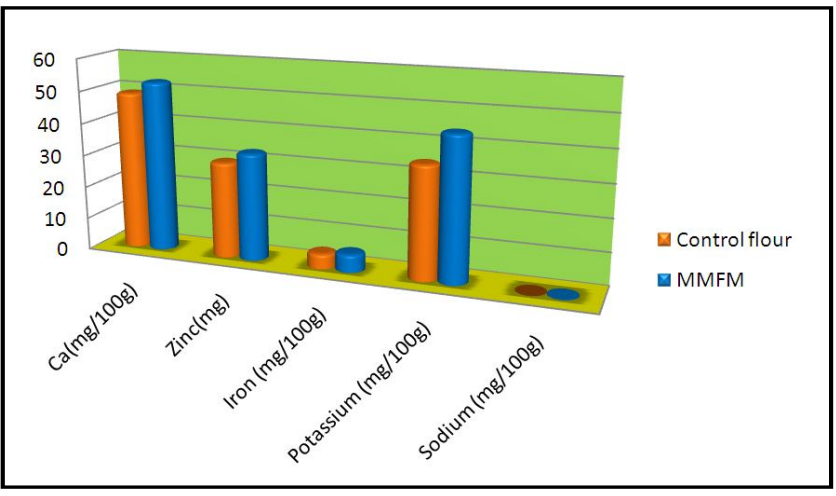

Figure 2: Mineral content of flour mixes.

\subsection{Total phenolic content and flavonoids}

Table 4 shows the total phenolic content of flour mixes. The total phenolic (240.2 GAE/100 g) and flavonoid (162 RE mg/100 g ) content of the MMFM was found to be higher than that of the control mix (106. $9 \mathrm{GAE}$ and $154 \mathrm{RE} / 100 \mathrm{~g}$ total phenol and flavonoids, respectively) (Table 4). Previously, Palanisamyet al. (2012) reported kodo millet as a rich source of phenolics in comparison to other millets. The outer layer of grain is considered the richest part in polyphenolic compounds (Awika et al., 2005; Liyana-Pathirana and Shahidi, 2007; Madhujith et al., 2006; Zielinski and Kozlowska, 2000). The main polyphenols in cereals are phenolic acids and tannins (Chandrasekara and Shahidi, 2010; Devi et al., 2011).

\subsection{Phytic acid}

MMFM had higher phytic acid content $(278.2 \mathrm{mg} / 100 \mathrm{~g})$ than control flour had $(206 \mathrm{mg} / 100 \mathrm{~g})$. The phytic acid increased in the experimental flour mix compared control flour mix. Similar findings have been reported by Chetana (2008) in different composite flour blends and chapathis. Phytates are thought to exhibit antioxidant properties by sequestering the iron before it can be involved in oxidation processes, thus, protecting against degenerative diseases. Furthermore, Pendelton (2009) reported that phytates can play a role in the reduction of digestion of starch, the glycaemic index of foods, cholesterol, and triglycerides production.

\subsection{Antioxidant activity}

The higher antioxidant content was observed in MMFM $(93.3 \mathrm{mg} /$ $100 \mathrm{~g}$ ) and a lower level in control flour $(85.70 \mathrm{mg} / 100 \mathrm{~g})$. Antioxidant activity increased with the incorporation of millet and other grains. Generally, the higher antioxidant activity of the mentioned fractions might be attributed to their contents of total polyphenols and especially flavonoids. However, according to Prior et al. (2005), many other compounds may contribute to the reaction and cause a false positive error. The main polyphenols in cereals are phenolic acids and tannins, whilst flavonoids are present in small quantities; they act as antioxidants and play many roles in the body's immune system defence (Chandrasekara and Shahidi, 2010; Devi et al., 2011).

\section{Discussion}

Present results revealed the moisture content decreased with addition of millet flour incorporation in MMFM. Chetana (2008) reported moisture content 11.50 per cent in composite mix I (pearl millet, sorghum, green gram and soybean) and 12.67 per cent in composite mix II (finger millet, sorghum, green gram, and soybean). In the present study, the moisture content might be low due to high fiber content, however low moisture content is a desirable attribute in increasing shelf life. Similary, the carbohydrate, energy of MMFM was decreased with addition of millets and other functional ingredients. Similarly, Roopa et al. (2003) had developed millet fortified dhokla mix and dhokla and reported that millet fortified dhokla energy decreased with an increased level of millet flour. Foxtail millet flour incorporated bread had an energy content of $257 \mathrm{kcal} / 100 \mathrm{~g}$. In contrast, the control bread had an energy content of $266 \mathrm{kcal} / 100 \mathrm{~g}$ (Chhavi and Sarita, 2012). Energy is essential for activity, growth and rest (Deepa, 2009).

The proximate composition of MMFM was found the addition of millets and functional ingredients enhanced the ash, fat, crude fiber content at significant levels. In this study, the mineral content was increased in MMFM due to millet grains have a high content of minerals and ash itself showing the high mineral content in milletbased foods, our findings are aligned with Kruppaswamy (2013) and Geetu et al. (2003) for different millets based composite flours. About 0.6 to $3.5 \mathrm{~g}$ is an adequate daily intake for sodium (Manay and Shadaksharaswami, 2006). Sodium and potassium are important constituents of fluid present outside and within the cells. Proper concentration of these electrolytes is essential to maintain osmotic balance (Gopalan et al., 2004).

Hence, the estimation of RS becomes essential in food samples. RS content of MMFM was sigificanlty higher compared to control flour mix. Foods containing RS will have a moderate rate of digestion. The slow digestion of RS has implications for its use in controlled glucose release applications. The digestion over a 5 to $7 \mathrm{~h}$ period reduces the postprandial glycemia insulinemia. It can increase satiety (Raben et al., 1994; Reader et al., 1997). Also, it helps to manage 
meal-associated hyperglycaemia (Lehmann and Robin, 2007); this is particularly important for people who are at risk of suffering from type 2 diabetes. The dietary fiber and in in vitro protein content was high in MMFM. It is recommended that an increase of dietary fiber, particularly the soluble type, should be taken by T2D patients (Wood et al., 1990; Slavin, 2005). It is reasoned that soluble fiber reduces enzyme access to its substrates through viscosity effect. Slavin (2005) has concluded that fiber intake and obesity are inversely correlated, indicating that fiber is an important instrument in starch and cholesterol control. The hypoglycaemic effect of dietary fiber could be due to the delaying the starch hydrolysis, glucose absorption and also improvement in glucose utilization and insulin sensitivity in target tissues (Wahlang, 2018).

The antioxidant and antinutritional content of MMFM were found significantly high compared to control flour. The total phenolic compounds are one of the most effective natural antioxidants. The present results revealed the higher content of TPC of MMFM can be attributed to millets, pulses and fenugreek presence in the mix. Similar results were reported by Ashoush and Gadallah (2011) in sprouted mug incorporated composite flour mix. Flavonoid also plays a protective role against cancer, cardiovascular diseases and kidney diseases and in vitro, flavonoid has shown free radical scavenging activity and protection against reactive oxygen species ( Shoba et al., 2010; Gu and Weng, 2001). The elevated antioxidant activity of MMFM might be due to the presence of the high amount of TPC and TFC.

In this study, phytic acid is a common storage form of phosphorus in seeds and is also considered as an antinutritional factor. The phytic acid content of MMFM $278.2 \mathrm{mg} / 100 \mathrm{~g}$ which is higher than the value reported by Abebe et al. (2007). Kruppaswamy (2013) reported that phytic acid has been shown to exhibit both áglycosidase and á- amylase inhibition in a dose-dependent manner, also shown to possess antidiabetic activity against streptozotocinnicotinamide induced diabetes (Type 2) rats.

\section{Conclusion}

The protein, fat, ash, and crude fibre, dietary fibre content was significantly higher in MMFM compared to wheat flour. The minerals, potassium, calcium, iron, and zinc content were significantly higher in composite flour than wheat flour. It would be an appropriate approach for providing balanced and required nutrients for diabetes. Blending techniques of nutrient-dense grains along with nutricereals will give required and balanced nutrients for reducing malnutrition and non-communicable diseases. Hence, it could be helpful in risk reduction of metabolic diseases.

\section{Conflict of interest}

The authors declare that there are no conflicts of interest relevant to this article.

\section{References}

Abebe, Y.; Bogale, A.; Hambidge, K. M.; Stoecker, B. J.; Bailey, K. and Gibson, R.S. (2007). Phytate, zinc, iron and calcium content of selected raw and prepared foods consumed in rural Sidama, Southern Ethiopia, and implications for bioavailability. J. Food Compost. Anal., 20(34): $161-168$

Ahmed, S.M.; Saleh, Qing Zhang.; Jing Chen and Qun Shen (2013). Millet grains: Nutritional quality, processing, and potential health benefits. Comprehensive Reviews in Food Science and Food Safety, 10:281-295.
American Diabetes Association (2018). Classification and diagnosis of diabetes: Standards of medical care in diabetes. Diabetes Care, 41(1):13-27.

Anitha, F.P. and Philip, A. (2001). Clinical Dietetics and Nutrition. Fourth edtion. Oxford Unversity, Press New Delhi, pp:347-356.

AOAC. (1980). Official methods for computation of carbohydrates and energy. Association of official analytical chemists. $14^{\text {th }}$ Edi. Washington, D.C. USA.

AOAC. (1990). Official methods of analysis for crude fiber. Association of official analytical chemists. $15^{\text {th }}$ Edi. Washington, D.C. USA.

AOAC. (1997). Official methods of analysis for fat (crude) or ether extract in flour. Association of official analytical chemists. $16^{\text {th }}$

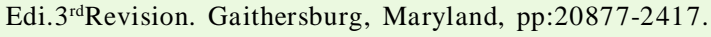

AOAC. (2005). Official methods of analysis for ash, moisture in flour. Association of official analytical chemists. $18^{\text {th }}$ Edition. Arlington VA 2209, USA. AOAC 929.09 \& 03, chap 32: 1-2.

Ashoush, I.S. and Gadallah, M.G.E.(2011). Utilization of mango peels and seed kernels powders as sources of phytochemicals in biscuit. World J. Dairy Food Science, 6(1):35-42.

Asp and Johansson (1981). In W. P. T. James, and O. Theander (Eds.), The analysis of dietary fiber in food, pp:173-189. New York: Marcel Dekker.

Awika, J. M.; McDonough, C. M. and Rooney, L. W. (2005). Decorticating sorghum to concentrate healthy phytochemicals. J. Agric. Food Chem., 53:6230-6234.

Bravo, L. (1998). Polyphenols: Chemistry, dietary sources, metabolism and nutritional significance. Nutri. Revie., 56:317-333.

Chandrasekara, A. and Shahidi. F. (2010). Content of insoluble bound phenolics in millets and their contribution to antioxidant capacity. J. Agriculture and Food Chem., 58:6706-6714.

Chausmer, A.B. (1998). Zinc , insulin and diabetics. J. American. Nutri., 7(2):109-115

Chethana, K.P. (2008). Development of value added products from millets and legumes. MSc Thesis, University of Agricultural Sciences. Bangalore. pp:1-117.

Chhavi, A. and Sarita, S. (2012). Evaluation of composite millet breads for sensory and nutritional qualities and glycemic response 89 evaluation of composite millet breads for sensory and nutritional qualities and glycemicresponse. Malaysian J. Nutri., 18(1):89101.

Choudhary, H. and Jood, S. (2013). Functional and nutritional characteristics of ragi wheat composite flour and its use in bread making. Asian J. Dairy. Food Resea., 32(2):120-125.

Deepa, S.P. (2009). Development of functional food formulation for diabetic and hypercholestrolemic subjects. M.Sc thesis. Foods and Nutrition Department. University of Agricultural Sciences GKVK, Bangalore.

Devi, P. B.; Vijayabharathi, R.; Sathyabama, S.; Malleshi, N. G. and Priyadarisini. V. B. (2011). Health benefits of finger millet (Eleusine coracana L.) polyphenols and dietary fiber: A review. J. Food Science and Techno., DOI: 10.1007/s13197-011-0584-9.

Dorman, H.J.; Bachmayer, O. M.;Kosar, R. and Hiltunen. (2004). Antioxidant properties of aqueous extracts from selected Lamiaceae species grown in Turkey. J. Agri. Food Chem., 52:762-770.

Geetu (2003). Development and nutritional evaluation of value added products from pearl millet (Pennisetum glaucum). M.Sc. Thesis, CCS Haryana Agricultural University, Hisar, India. 
Goni, I.; Garcia-Diz, L.; Manas, E. and Saura-Calixto, F. (1996). Analysis of resistant starch: A method for foods and food products. Food Chem., 56(4):445-449.

Gopalan, C.; Sastri, R. and Balasubramanian, S.C. (2004). Nutritive value of Indian foods. National Institute of Nutrition, Indian Council of Medical Research, Hyderabad, India.

Gu, L. and Weng, X. (2001). Antioxidant activity and components of Salvia plebeia R. Br.: A Chinese herb. Food Chem., 73(3):299305 .

Hameeda, B.; Itagi, N. and Vasudeva Singh. (2012). Preparation, nutritional composition, functional properties and antioxidant activities of multigrain composite mixes. J. Food Sci. Technol., 49(1):74-81.

Indian Diabetes Federation (2019). $9^{\text {th }}$ edi.Global and regional diabetes prevalence estimates for 2019 and projections for 2030 and 2045.

Indrani, D.; Swetha, P.; Soumya, C.; Jyotsna, R.G. and Venkateswara, R. (2011). Effect of multigrains on rheological, microstructural and quality characteristics of north Indian parotta an Indian flat bread. Food Sci. Technol., 44:719-724.

Jenkins, D.J.; Wolever, T.M.; Leeds, A.R.;Gassull, M.A.;Haisman, P.; Dilawari, J.; Goff, D.V, Metz, G.L. and Alberti, K.G. (1978). Dietary fibres, fibre analogues, and glucose tolerance: Importance of viscosity. Br. Med. J., 1:1392-1394.

Johnston, K.L.; Thomas, E.L.; Bell, J.D.; Frost, G.S.and Robertson, M.D. (2010). Resistant starch improves insulin sensitivity in metabolic syndrome. Diab. Medi., 27(4):391-397.

Kadam, M.L.; Salve, R.V.;Mehrajfatema, Z.M. and More, S.G. (2012) Development and evaluation of composite flour for Missiroti / chapatti. J. Food. Proce. Technol., 3:1-5.

Karuppasamy, P. (2013). Standardization and evaluation of therapeutic foods from foxtail millet (Setaria italica), little millet (Panicum miliare), kodo millet (Paspalumscr obiculatum) and its impact study on diabetes. Ph.D thesis. Tamilnadu Agricultural University Madurai.

Kaveeshwar, S. A. and Cornwall, J. (2014). The current state of diabetes mellitus in India. Aust. Medi. J., 7(1):45-48.

Kotagi, K.; Chimmad, B.;Itagi, S. and Bharati, P. (2013). Glycemic index and quality evaluation of ready to cook little millet (Panicum miliare) flakes, Proc international workshop on small millet research in value addition, IDRC, 94. UAS, Dharwad (India).

Kulkarni, K.D. and Ingle, U.M.(1991). Sorghum malt-based weaning food formulations: Preparation, functional properties, and nutritive value. Food. Nutri. Bull., 13(4):322-327.

Lakshmi, M.; Swarnali, D, M. and Usha Rav. (2015). Development and analysis of composite flour bread. J. Food. Scie. Technol., 52(7):41564165 .

Laminu, H.H.; Modu, S. and Numan, A. I. (2011). In vitro protein digestibility, phytate content and acceptability of weaning foods prepared from pearl millet (Pennisetum typhoideum) and cowpea (Vigna unguiculata). Inter. J. Nutri. Meta., 3(9):109-113.

Lehmann, U. and Robin, F. (2007). Slowly digestible starch - its structure and health implications: A review. Trends Food. Sci. Technol., 18: $346-355$.

Lin, H.C.; Zhao, X.T. and Wang, L.(1996). Fat absorption is not complete by midgut but is dependent on load of fat. Ameri. J. Phy., 271:62-67.

Liyana-Pathirana, C. M. and Shahidi, F. (2007). Antioxidant and free radical scavenging activities of whole wheat and milling fractions. Food Chem., 101:1151-1157.
Madhujith, T.; Izydorczyk, M. and Shahidi, F. (2006). Antioxidant properties of pearled barley fractions. J. Agric. Food Chem., 54:3283-3289.

Malathi, D. (2014). Study on nutrient composition of millets and ways to minimize loss during processing and value addition. Post harvest technology centre agricultural engineering college and research Institute Tamil Nadu Agricultural University. Tamilnadu.

Manay, N. S. and Shadaksharaswamy, M. (2006). Foods Facts and Principles, 2nd edi, New age International (P) Ltd, New Delhi, pp:246-247.

Martin-Cabrejas, M.A.; Ariza, N. andEsteban, R.(2003). Effect of germination on the carbohydrate composition of the dietary fibre of peas (Pisum sativum L.). J. Agri. Food. Chem., 51:1254-1259.

Palanisamy, B. D.; Rajendran, V.; Sathyaseelan, S.; Bhat, R and Venkatesan, B. P. (2012). Enhancement of nutritional value of finger millet-based food (Indian dosa) by co-fermentation with horse gram flour. Int. J. Food. Sci. Nutri., 63(1):5-15.

Pendelton, J. (2009). Challenges and possibilities of inositolhexaphosphate, http://nutrition.suite 101.com/article.cfm/phytates.

Poongodi, V.T. and Mohankumar, J.B. (2009). Formulation and characterization of millet flour blend incorporated composite flour. Int. J. Agri. Sci., 1(2):46-54.

Premavalli, K.S. and Sathayanaraswamy, Y.S., Madhura, C.V., majumdar, T.K and Bawa. (2005). J. Food.Scie. Technol., 42(5):443-445.

Preuss, H.G. (2001). Sodium, chloride and potassium.present knowledge in nutrition, Eds. Bowman and Russell, 8th ed., Washington, DC, :302-310.

Prior, R.L.; Wu, X. and Schaich, K. (2005). Standardized methods for the determination of antioxidant capacity and phenolics in foods and dietary supplements. J. Agri. Food Chem., 53:4290-4302.

Priyanka, T.; Anushriya S.; Pratima,A. and Anupama, P.(2018). Quality analysis of composite flour and its effectiveness for chapatti formulation. J. Pharmac. Phytochem., 7(4):1013-1019.

Raben, A.; Tagliabue, A.; Christensen, N.J.; Madsn, J.; Holst, J. and Astrup, A. (1994). Resistant starch: The effect on postprandial glycemia, hormonal response and satiety. Ame. J. Clin. Nutri., 60:544551 .

Ragaee, S. and Abddel Aal, E.S.M. (2006). Pasting properties of starch and protein in selected cereals and quality of their food products. Food Chem., 95(1):9-18.

Reader, D.; Johnson, M.L.; Hollander, P. and Franz, M. (1997). Response of resistant starch in a food bar vs. two commercially available bars in persons with type II diabetes mellitus. Diabetes, 46:254.

Roben, A.; Tagliabue, A.; Christensen, N.J.;Madsn, J.;Hoslst, J. and Astrub, A. (1994). Resistant starch, the effect on postprandial glycemia, hormonal response an satiety. Ame. J. Clin. Nutri., 60:544-51.

Roopa, S.; Premavalli, K.S. and Bawa, A.S. (2003). Development of a traditional product (Halibai mix) based on millet. In: Poster abstracts of 5th IFCON. 5-8 December. CFTRI, Mysore. India. 167.

Shoba, G.; Hari, S.; Prabhavathi, G. and Stella, S. (2010). Flavonoids-natural therapeutic agents for polycystic kidney disease. Int. J. Pharm. Biol. Sci., 1(4):B89-B105.

Singh, P.; Singh, G.; Srivastava, S. and Agarwal, P. (2005). Physico-chemical characteristics of wheat flour and millet flour blends. J. Food Sci. Technol., 42(4):340-343.

Singh, U. and Jambunathan, R. (1981). Studied on desi and kabuli chickpea cultivators. The level of amylose inhibitors, level of oligosaccharides and in vitro protein digestibility. J. Food Sci., 46:1364.

Slavin, J. L. (2005). Dietary fiber and body weight. Nutrition, 21:411418. 
Slinkard, K. and Singleton, V.L. (1997). Total phenol analysis: Automation and Comparison with manual Methods. Ame.J. Enolo. Viticul., 28:49-55.

Srilakshmi, N. (2001). Diet in in diabetes milletus. In dietetics NEW delhi. New Age international Pvt Ltd.

Sujatha. M. (2015). Effect of heat treatment and gamma irradiation on in vitro starch digestibility (IVSD), In vitro protien digestibility (IVPD), and total phenolics (Tp) of selected millet grain. M.Sc Thesis. Foods and Nutrition Department, Professor Jayashanakar Telangana State Agricultural University.

Tabita, K.M.; Kexue, Z.; Amadou. I.; Tarawalie Fatmata and Huiming Zhou. (2009). Functionality, in vitro digestibility and physicochemical properties of two varieties of defatted foxtail millet protein concentrates. Int. J. Mole. Sci., 10:5224-5238.

Vijayalakshmi, $\mathbf{P}$ and Radha, R. (2006). Effect of little millet supplementation on hyperlipidemia.The Indian. J. Nutri. Diete., 43(11):469-474.
Wahlang, B.; Joshi, N. and Ravindra, U. (2018). Glycemic index lowering effect of different edible coatings in foxtail millet. J. Nutri. Health.Food. Eng., 8(6):404-408.

Wheeler, E.C. and Ferrel, P. E. (1971). A method for phytic acid determination in wheat and wheat fractions. Cereal Chem., 48:312-320.

Wood, P. J.; Braaten J. T.; Scott, F. W.; Riedel, D and Poste, L. M.(1990). Comparisons of viscous properties of oat and guar gum and the effects of these and oat bran on glycemic index. J. AgrI. Food Chem., 38:753-757.

Zhishen, J.; Mengcheng, T. and Jianming, W. (1999). The determination of flavonoid contents in mulberry and their scavenging effects on superoxide radicals. Food Chem., 64:555-559.

Zielinski, H. and $\mathrm{Koz}^{3} \mathbf{o w s k a}$, H. (2000). Antioxidant activity and total phenolics in selected cereal grains and their different morphological fractions. J. Agric. Food Chem., 48:2008-2016. 